\title{
Mesenteric Cystic Lymphangioma in Pediatric Patient: A Rare Intra-Abdominal Tumor Management in Rural Country Case Report
}

\author{
Perdhana Kusuma*(iD), Muhammad David Perdana Putra ${ }^{\mathbb{D}}$, Suwardi Suwardi \\ Department of Surgery, Faculty of Medicine, Sebelas Maret University, Surakarta, Indonesia
}

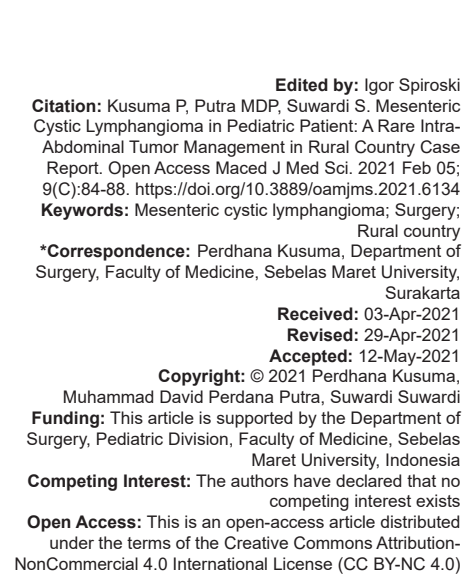

Introduction

Mesenteric cystic lymphangiomas (MCLs) are rare congenital benign malformations of the lymphatic system that is usually located in the small-bowel mesentery, followed by the omentum, mesocolon, and retroperitoneum, with an incidence of 1 case/250,000 hospital admissions [1], [2]. MCLs are more frequent in boys (5:2) with a mean age at presentation of 2 years [3]. Clinical presentation varies from asymptomatic masses to acute abdominal pain. Because of variable and non-specific clinical symptoms and signs, they are discovered either accidentally during an abdominal radiological examination for other reasons or during laparotomy for the management of one of the complications. The etiology of such cysts remains unknown but several theories regarding their development exist. Complete surgical excision of the cyst is the treatment of choice. Due to the rarity of this entity and the lack of specific symptoms, correct pre-operative diagnosis is difficult. Knowledge of these lesions is important due to the various complications associated with suboptimal surgical management [2].

\section{Case Report}

A 4-year-old girl, native of Surakarta, presented to the emergency room with a chief complaint of profuse bilious vomiting of more than 10 times/day. The patient had a history of dull aching intermittent pain on the right side of abdomen for 5 months, particularly after meals. A lump was noticed on the right side of abdomen by the parent of the child, which was increasing gradually. There was no history of fever, jaundice, melena, hematemesis, bleeding per rectum, dysuria, hematuria, chronic cough, hemoptysis, bony pains, seizures, or worm infestation. There was no family history of similar disease or any congenital anomaly. On the clinical examination, vital parameters were found within a normal limit with no pallor, icterus, pedal edema, and lymphadenopathy. The abdomen examination revealed a well-defined oval shape, intra-abdominal lump, extending from umbilical to right iliac fossa, cystic in consistency, non-tender, with well-defined margins. It was slightly mobile from side to side. Laboratory tests found hemoglobin count of $13.1 \mathrm{~g} / \mathrm{dL}$, hematocrit of $39 \%$, white blood cells count of $9.900 / \mathrm{uL}$, and platelet count of $445.000 / \mathrm{uL}$. 
Her blood differential showed $93 \%$ neutrophils, $5.1 \%$ lymphocytes, $0.0 \%$ eosinophils, and $0.22 \%$ basophils. Her liver function tests and urinalysis were within normal limits. A chest radiograph showed no infiltrates in lungs. Abdominal X-ray was performed, and no sign of ileus was found (Figure 1). Initial abdominal ultrasonography (USG) showed a cystic mass measuring $7.17 \times 3.3 \mathrm{~cm}$ at umbilical to suprapubic. The mass included a welldefined cystic lesion divided by thin internal septa (Figure 2). Abdominal computed tomography (CT) scan with contrast revealed an intra-abdominal cystic mass, measuring $9.1 \times 4.7 \times 9.1 \mathrm{~cm}$ in dimension, with feeding artery from A. mesenterica superior (Figure 3).

Therefore, the patient was prepared for exploratory laparotomy and excision of cyst. She underwent exploratory laparotomy. The tumor was located $10 \mathrm{~cm}$ from the Treitz ligament, which revealed a giant, soft, cystic, serous fluid-filled mass in the mesentery of jejunum (Figure 4). Next, we excised the tumor mass, performed jejunal resection of the involved loops which was necessary, and sent the tissue samples for histopathological examination. Histopathological examination confirmed a diagnosis of mesenteric uniloculated cystic lymphangioma (Figure 5). Postoperatively, the patient received broad spectrum antibiotics and analgesics appropriately. The patient was discharged uneventfully at the $4^{\text {th }}$ postoperative day and was asymptomatic on clinical follow-up after 6 weeks.
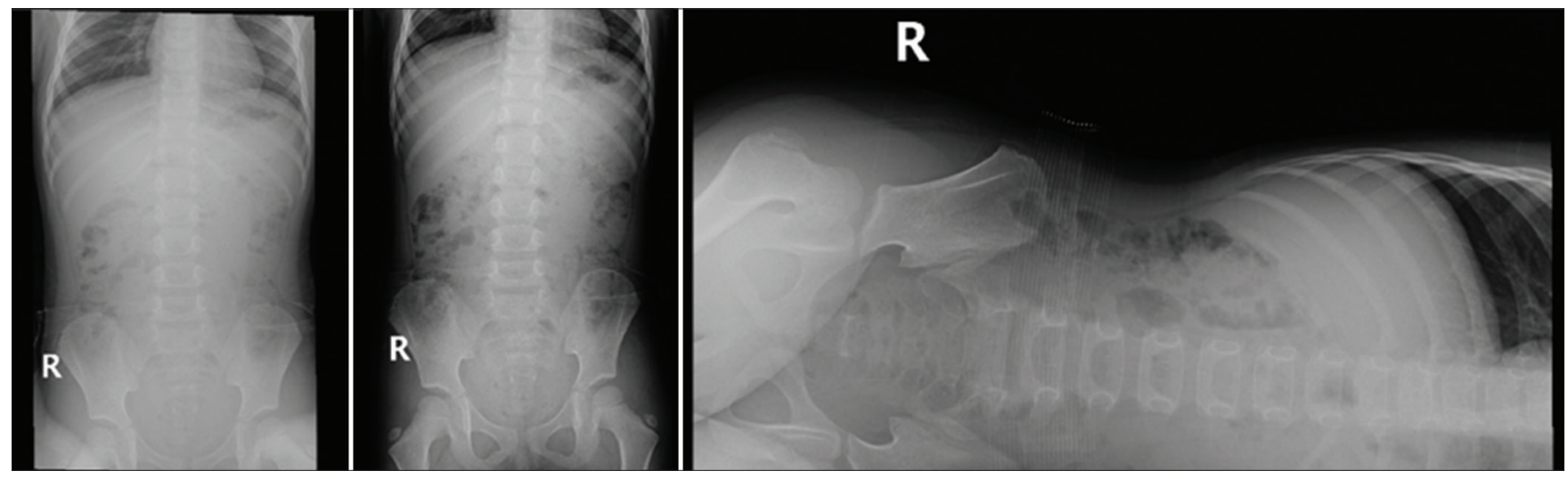

Figure 1: Abdominal X-ray not showing any bowel dilatation or air fluid levels
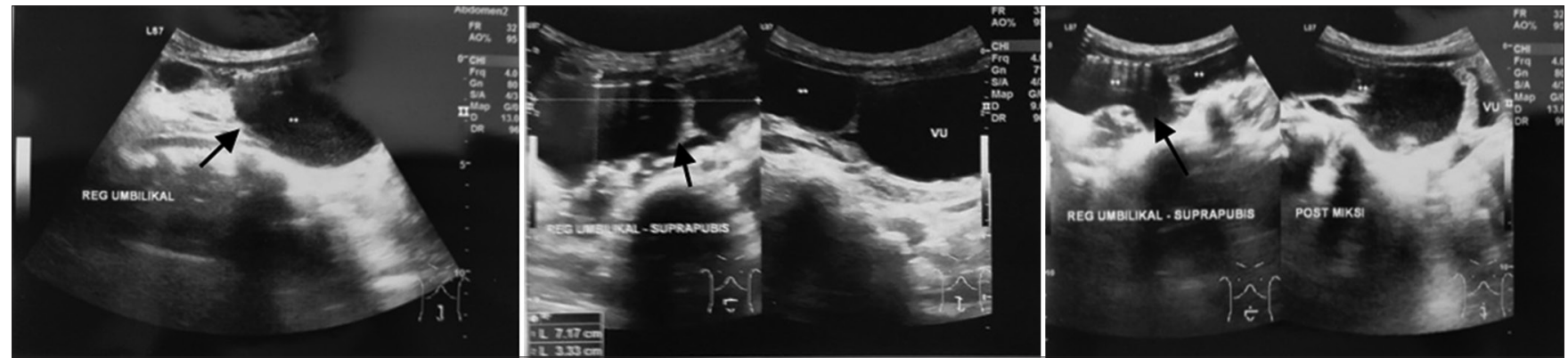

Figure 2: Intra-abdominal mass found on ultrasonography
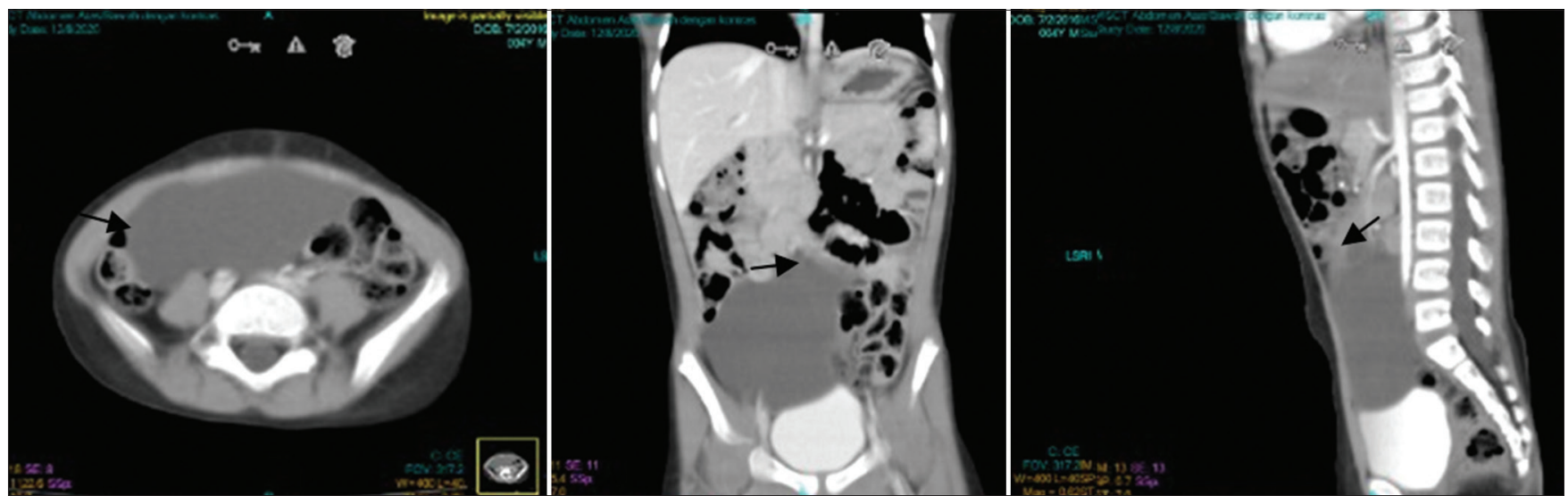

Figure 3: Computed tomography scan illustrating a large cystic mass pushing against a loop of small bowel 


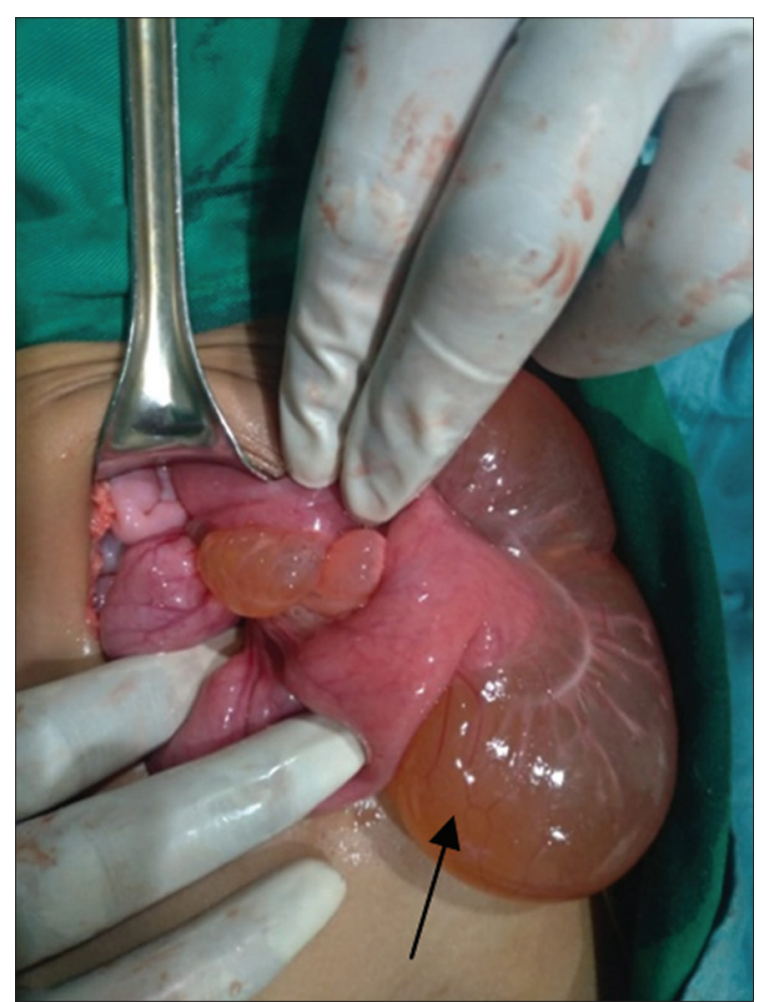

Figure 4: Mesenteric cyst extending from umbilical to right iliac fossa

\section{Discussion}

MCLs are rare surgical condition occurring approximately in 1/200,000-350,000 hospital admissions [4]. An Italian anatomist, Benevenni first described this entity performing an autopsy in an 8-year-old boy in 1507, while Rokitansky published the first accurate description of a chylous mesenteric cyst in 1842 and Tillaux performed the first successful surgery for a cystic mass in the mesentery in 1880 [5].

A MCL is defined as any cyst located in the mesentery; it may or may not extend into the retroperitoneum, which has a recognizable lining of endothelium or mesothelial cell. MCL can occur anywhere in the mesentery of gastrointestinal tract from duodenum to rectum. In a review series of 162 patients, $60 \%$ of mesenteric cysts occurred in the small-bowel mesentery, $24 \%$ in the large bowel mesentery, and $14.5 \%$ in the retroperitoneum while it was indefinite in $1.5 \%$ of cases [6]. Lymphangiomas account for about $5-6 \%$ of all benign tumors in infants and children [2], [5]. About $50 \%$ of cases involve the head and neck, with only $10 \%$ occurring in internal organs [4]. About $60 \%$ of these masses are present at birth. MCLs are very uncommon. Almost $90 \%$ are detected by the mean age of 2 years, and most occur in the mesentery of the small bowel [6].

MCLs can be simple or multiple, unilocular, or multilocular, and they may contain hemorrhagic,

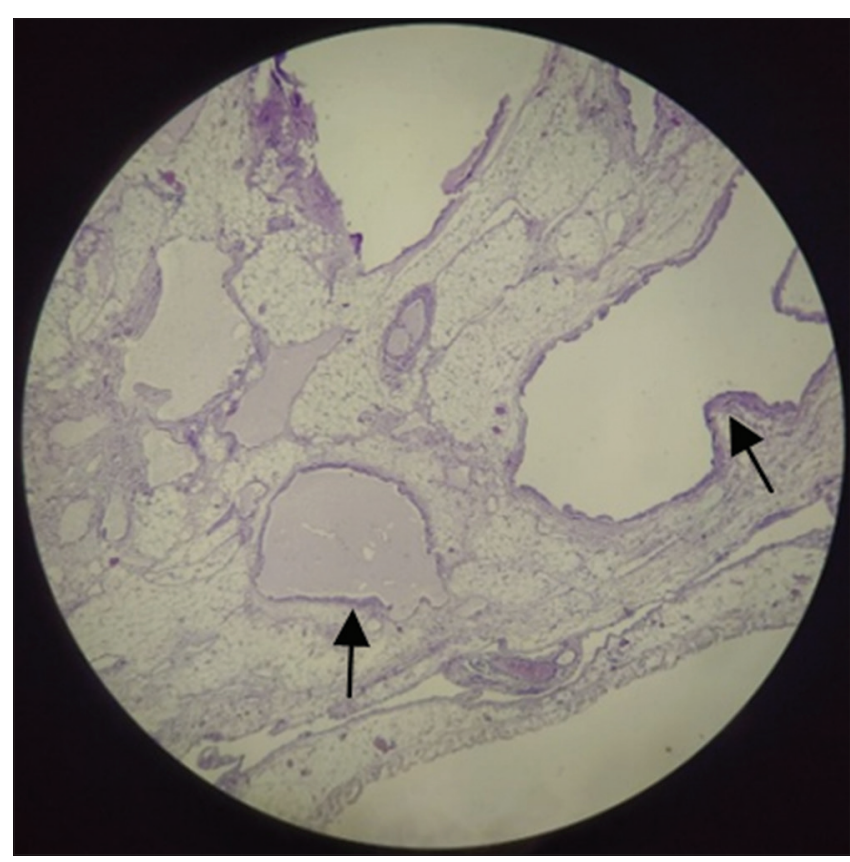

Figure 5: Tissue samples stained using hematoxylin and eosin. Histopathological view showing the dilated cystic spaces, coated with endothelial, contained amorphous eosinophilic fluid, supporting the diagnosis of lymphangioma

serous, chylous, or infected fluid. They can range in size from a few millimeters to a few centimeters in diameter; however, at times, they may be so large that they may mimic tubercular ascites [7]. Exact etiology of mesenteric cyst has yet to be ascertained, but failure of the lymph nodes to communicate with the lymphatic or venous systems or blockage of the lymphatics as a result of trauma, infection, and neoplasm is said to be the contributing factor [8]. The most accepted theory, proposed by Gross, is benign proliferation of ectopic lymphatics in the mesentery that lacks communication with the remainder of the lymphatic system [9].

MCL may occur in patients of any age. Approximately one-third of cases occur in children younger than 15 years old. The cyst may present either as non-specific abdominal feature, as an incidental finding, or as an acute abdomen. It is often asymptomatic and found incidentally while patients are undergoing work-up or receiving treatment for other conditions, such as appendicitis, small-bowel obstruction, or diverticulitis although patients may present with lower abdominal pain and symptoms that are frequently associated with other abdominal conditions. The symptoms are variable and non-specific and include pain ( $82 \%)$, nausea and vomiting $(45 \%)$, constipation $(27 \%)$, and diarrhea $(6 \%)$. An abdominal mass may be palpable in up to $61 \%$ of patients [10].

MCL should be evaluated with complete history, clinical examination, blood investigations, and radiological investigations (X-ray abdomen erect, 
ultrasound abdomen, and CT scan in selected cases) to reach a provisional diagnosis [11]. On CT scans, they usually appear as a smooth-margined unilocular or multilocular cystic mass with homogeneous fluid attenuation and density ranging from -4 to -34 Hounsfield units [3]. The diagnosis is proven on laparotomy and has to be histologically confirmed. Secondary complications associated with mesenteric cysts include volvulus, spillage of infective fluid, herniation of bowel into an abdominal defect, and obstruction [11]. The treatment of choice is complete excision to avoid recurrence and possible malignant transformation. Bowel resection may be necessary in cases where cysts are close to bowel structures or involve blood vessels that supply the bowel. Once removed, MCLs rarely recur, and patients have an excellent prognosis. Malignant cysts occur in $<3 \%$ of cases [12].

The definitive treatment for MCL is complete surgical excision. During surgery, as was the case with our patient, it is often necessary to perform a bowel resection because of the close relation between the cyst and the intestinal wall. Some authors recommend conservative management in asymptomatic patients, based on $10 \%$ spontaneous regression rate reported in these patients [1], [13]. Aspiration and injection of sclerosant agents may be recommended for emergency decompression, but as definitive therapy, they have a high recurrence rate. Other treatments such as OK-432, bleomycin, steroids, fibrin glue, and Ethibloc have not demonstrated superior results to surgery in MCL [13], [14]. The advent of laparoscopic surgery has allowed resection of these cysts to be achieved without full laparotomy. Laparoscopic exploration using four ports after insufflation with Veress needle and excision of cyst using cautery scissors and blunt dissection. Endobag is then used to retrieve the cyst. Laparoscopic excision allows early return of patient to his work [15].

\section{Conclusion}

MCLs may be invasive and grow to an enormous size but are not malignant hence possesses good prognosis. Clinically, mesenteric lymphangiomatosis is a rare entity, but should be considered in a child with bowel obstruction and no other known abdominal disease. In case of suspicion of a mesenteric mass, complete resection is the treatment of first choice, with low recurrence rate and a non-complicated postoperative period.

\section{References}

1. Alqahtani A, Nguyen LT, Flageole $H$, Shaw K, Laberge JM. 25 years' experience with lymphangiomas in children. J Pediatr Surg. 1999;34(7):1164-8. https://doi.org/10.1016/ s0022-3468(99)90590-0

PMid: 10442614

2. Pithawa AK, Bansal AS, Kochar SP. Mesenteric cyst: A rare intraabdominal tumour. Med J Armed Forces India. 2014;70(1):79-82. https://doi.org/10.1016/j.mjafi.2012.06.010

PMid:24936122

3. Konen O, Rathaus V, Dlugy E, Freud E, Kessler A, Shapiro M, Horev G. Childhood abdominal cystic lymphangioma Pediatr Radiol. 2002;32(2):88-94. https://doi.org/10.1007/ s00247-001-0612-4

PMid: 11819071

4. Bono D, Tomaselli F, Caponi R, Saracco R. Laparoscopic excision of a voluminous mesenteric cyst: Case report of a rare entity and review of literature. Int J Surg Case Rep. 2020;77(Suppl 1):S64-6. https://doi.org/10.1016/j.ijscr.2020.10.042

PMid:33172813

5. Mohanty SK, Bal RK, Maudar KK. Mesenteric cyst--an unusual presentation. J Pediatr Surg. 1998;33(5):792-3. https://doi. org/10.1016/s0022-3468(98)90224-x

PMid:9607505

6. Saviano MS, Fundarò S, Gelmini R, Begossi G, Perrone S Farinetti A, Criscuolo M. Mesenteric cystic neoformations: Report of two cases. Surg Today. 1999;29(2):174-7. https://doi. org/10.1007/bf02482245 PMid: 10030745

7. Zamir D, Yuchtman $M$, Amar $M$, Shoemo $U$, Weiner $P$. Giant mesenteric cyst mimicking ascites. Harefuah. 1996;130(10):683-4, 727

PMid:8794659

8. Beahrs OH, Judd ES Jr., Dockerty MB. Chylous cysts of the abdomen. Surg Clin North Am. 1950;30(4):1081-96. https://doi. org/10.1016/s0039-6109(16)33090-0

PMid: 15442870

9. Richard RR. Mesenteric and omental cysts. In: Grosfeld JL, O'Neill JA Jr., Coran AG, Fonkalsrud EW, editors. Pediatric Surgery. $6^{\text {th }}$ ed. Philadelphia, PA: Mosby Elsevier; 2006. p. $1399-406$.

10. Prakash A, Agrawal A, Gupta RK, Sanghvi B, Parelkar S Early management of mesenteric cyst prevents catastrophes: A single centre analysis of 17 cases. Afr J Paediatr Surg. 2010;7(3):140-3. https://doi.org/10.4103/0189-6725.70411 PMid:20859015

11. Hassan M, Dobrilovic N, Korelitz J. Large gastric mesenteric cyst Case report and literature review. Am Surg. 2005;71(7):571-3. https://doi.org/10.1177/000313480507100706 PMid: 16089120

12. Kurtz RJ, Heimann TM, Holt J, Beck AR. Mesenteric and retroperitoneal cysts. Ann Surg. 1986;203(1):109-12. PMid:3942415

13. Steyaert H, Guitard J, Moscovici J, Juricic M, Vaysse P, Juskiewenski S. Abdominal cystic lymphangioma in children: Benign lesions that can have a proliferative course. J Pediatr Surg. 1996;31(5):677-80. https://doi.org/10.1016/ s0022-3468(96)90673-9

PMid:8861480

14. Losanoff JE, Richman BW, El-Sherif A, Rider KD, 
Jones JW. Mesenteric cystic lymphangioma. J Am Coll Surg. 2003;196(4):598-603. s1072-7515(02)01755-6

PMid:12691938
15. Resta G, Tartarini D, Fabbri N, Bianchini E, Anania G Laparoscopic resection of a jejunal mesenteric pseudocyst: Case report. G Chir. 2014;35(11-12):279-82.

PMid:25644729 